Acta Technologica Agriculturae 4

Nitra, Slovaca Universitas Agriculturae Nitriae, 2015, pp. 108-112

\title{
INTENSIFICATION OF THE PROCESS OF PREPARING SMALL SEED CROP MIXTURES
}

\author{
Stepan KOVALYSHYN ${ }^{1 *}$, Viktor DADAK ${ }^{1}$, Stanislav KONYK² \\ ${ }^{1}$ Lviv National Agrarian University, Ukraine \\ ${ }^{2}$ Carpathian Institute of Agriculture of Western Region NAASU, Ukraine
}

The process of preparing small seed mixtures, especially of perennial cereal grasses, is intensified by certain difficulties. Research has shown that the process of separating mixtures can be enhanced by using a high-voltage electric field. As a result, the separation of quality seed and the seed without an embryo occurs.

Keywords: small seed; pneumatic electric separation; geometrical parameters; internal and external friction

In Ukraine, about 5 million hectares or about $20 \%$ of agricultural land produces small seed crops. These include seeds with a weight less than $5 \mathrm{~g}$ per 1000 seeds (Zhuk, 2012). They are mainly vegetables, oil crops and a great number of forage grasses (Table 1).

Table 1 Sowing structure for small seed crops in Ukraine

\begin{tabular}{|l|c|c|}
\hline $\begin{array}{l}\text { Types of small seed } \\
\text { agricultural crops }\end{array}$ & $\begin{array}{c}\text { Crop acreage, } \\
\text { thousand hectares }\end{array}$ & $\begin{array}{c}\text { Percentage in the } \\
\text { structure of acreage }\end{array}$ \\
\hline Vegetables & 500 & 2 \\
\hline Oil crops & 2500 & 10 \\
\hline Forage grasses & 2000 & 8 \\
\hline Total & 5000 & 20 \\
\hline \multicolumn{2}{|c|}{ Note: sowing acreage for agricultural crops in Ukraine }
\end{tabular}
is up to 25000 hectares

To obtain high yields of these crops, it is necessary to have a sufficient number of high-quality seeds. They are produced as a result of treatment in the post-harvest period, which currently needs a significant improvement (Chyzhykov, 2001). The problem of sowing material preparation of small seed crops is that equipment cannot provide highquality purification of seeds. As a result, in some separation processes, a large number of good conditional seeds are wasted and made impossible to separate weeds from seeds.

The main reason for this is that most clearing machines separate seed mixtures in pneumatic crate indented cylinders or frictional working cylinders. To use either of them, physical and mechanical properties of seeds are considered. However, both crop seeds and weed seeds of small seed mixtures lack dominant segregation features, since there is very little difference in size, shape and friction. Because of this, there is a lack of proper effective means for clearing seeds of alfalfa, clover, timothy, perennial ryegrass, carrots, parsley, celery, fennel, onions, spring and winter rape, flax, etc. (Tarushkyn, 2007). Losses of conditional (full value) seeds in the process of their clearing amount to $20-50 \%$ (Kovalyshyn, 2013). Increase of the output of cleared seeds, e.g. perennial grasses, by $1 \%$ will lead to the extension of crop acreage by more than 20 ha on a nationwide scale (Tarushkyn, 2007).

Therefore, there is a need to design machines that would not only operate with physical and mechanical properties of seeds but also biological. To solve these problems in the process of separating the sowing material of small seed mixtures, we can apply electric field as an additional working body. According to the data (Kovalyshyn, 2014), a pneumatic electric separator can be used as one of such machines where seeds are separated, taking into account the combination of electric and aerodynamic properties of mixture components (Dadak, 2013).

\section{Material and methods}

To determine the effectiveness of pneumatic electric separation, we have chosen seeds of the most common grasses located in the western region of Ukraine. These include perennial ryegrass and false oat-grass, meadow fescue, Bromus inermis, orchard grass and also couch grass and lungwort weeds as weeds that are difficult to be separated. The research includes: assessment of the external surface using photographs taken by an electron microscope; identification of the main physical and mechanical properties of crop seed and weeds; identification of the content of substandard seeds in the initial and in separated mixtures by means of X-ray; and determination of pneumatic electric separation effectiveness.

The assessment of conditions of the outer surface of cereal grasses and weeds seeds has been performed on the basis of their photographs analysis. The photos were taken by the scanning electronic microscope (SEM) JEOLT220A. When taking a picture, we have enlarged the photo in 35-50 times. Preparation of samples for study in SEM 


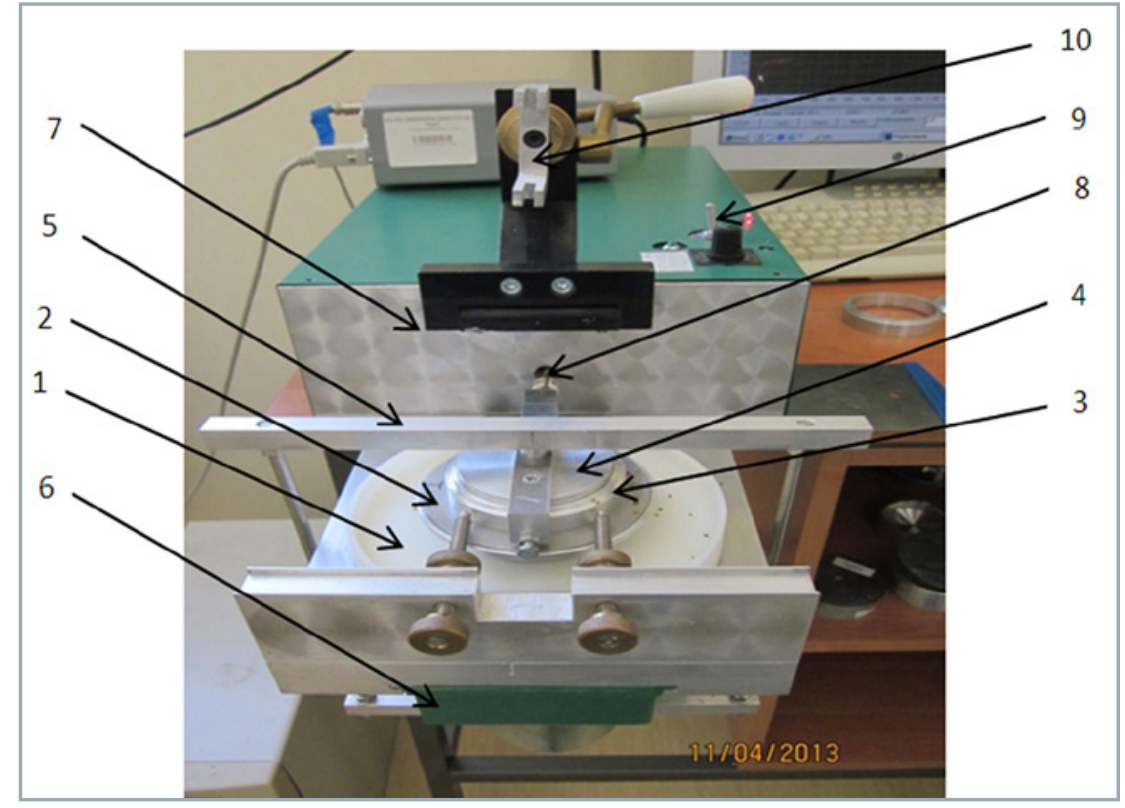

Figure 1 Jenikiego device

1 - bed; 2 - investigated surface; 3 - without a bottom ring $D=60 \mathrm{~mm} ; 4$ - ring cover; 5 - set of bobs to create a vertical load; 6 - seed capacity; 7 - control unit (setting the velocity of the ring with seeds from $0 \mathrm{~mm} \cdot \mathrm{min}^{-1}$ to $5 \mathrm{~mm} \cdot \mathrm{min}^{-1}$ ); 8 effort sensor; 9 - effort direction latch lever; 10 - lever for seed sealing

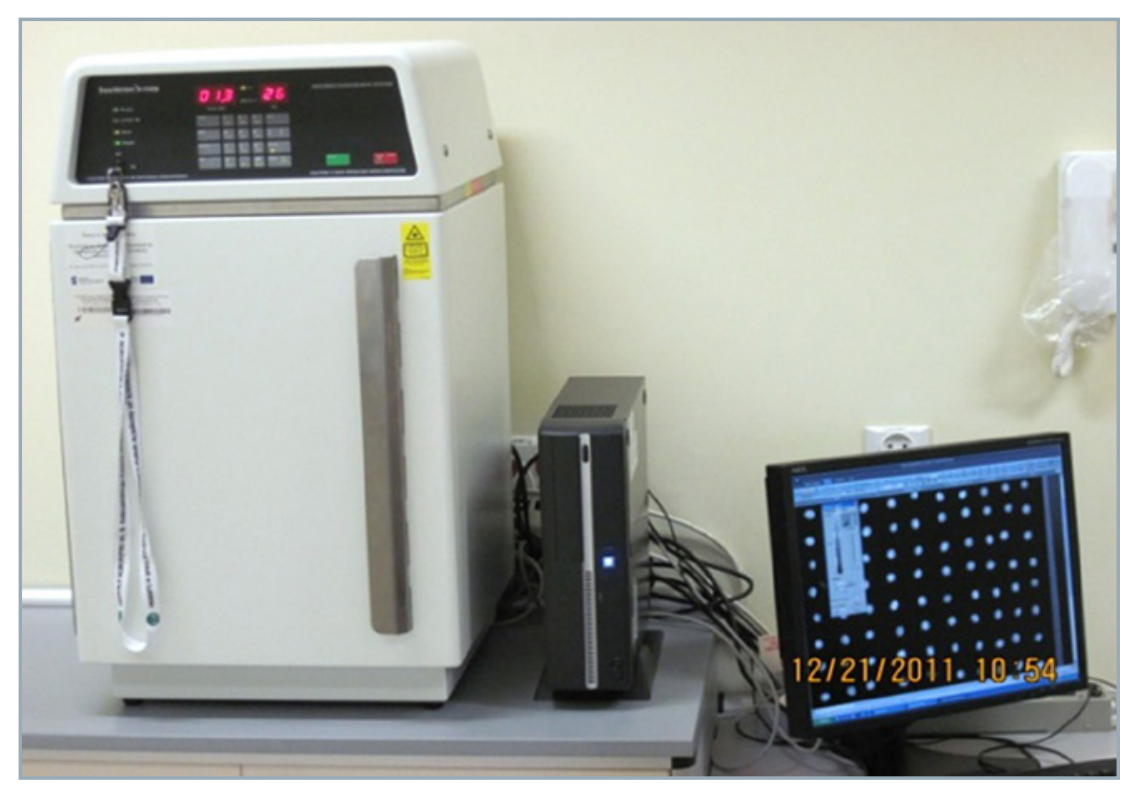

Figure 2 Faxitron MX-20 device

includes two procedures - fixation and metallisation of the sample surface. Due to SEM photographing, we obtained images of the studied cereal grasses seeds that enabled us to assess the state of the seed surface, to detect existing damages, to reveal characteristic morphological features that would provide the possibility for their separation, etc.

We have determined the basic geometrical parameters such as length, width and thickness using
The study of qualitative seed material output was made with samples after performing the pneumatic electric separation using the X-raying of 1000 seeds by a Faxitron MX-20 device (Figure 2).

The X-rays taken were displayed on a computer monitor. Their analysis allowed us to determine the amount of substandard seeds without embryos in each sample.

For conducting experimental tests on separation of such seeds from the basic mass, we have used the upgraded design of pneumatic electric separator (Kovalyshyn, 2013); the general view is shown in Figure $3 \mathrm{~A}$ and the technological operation scheme is shown in Figure 3B.

The characteristic of this separator is the existence in separation channel 10 of two electrodes 17 located opposite to each other, and fed with high voltage. Delivery of separating mixture from loading bunker 8 to separation channel 10 is provided by means of regulated vibration feeder 9 .

The rate of air flow in the channel was provided by the change of fan frequency applying an ASF 110 frequency converter.

\section{Results and discussion}

The process of preparing small seed mixtures, especially of perennial cereal grasses, is complicated. This is primarily due to poor-quality seeds that fail to meet the requirements of DSTU 7160 (2010) with:

- Increased content of weeds impurities, especially those hard-to-divide.

- The presence of a large number of biologically inferior, dead seeds without embryos.

In order to increase the effectiveness of the preparation process of small seed mixtures, especially separation, one should obtain sufficient knowledge and experimental data about the properties of both seed crops and weeds. First of all, information about the physical and mechanical properties, morphological characteristics and features, and a range of changes in these properties. Based on the synthesis of such data, one can seek out new features of divisibility, assert the possibility of quality clearing of studied mixtures, 


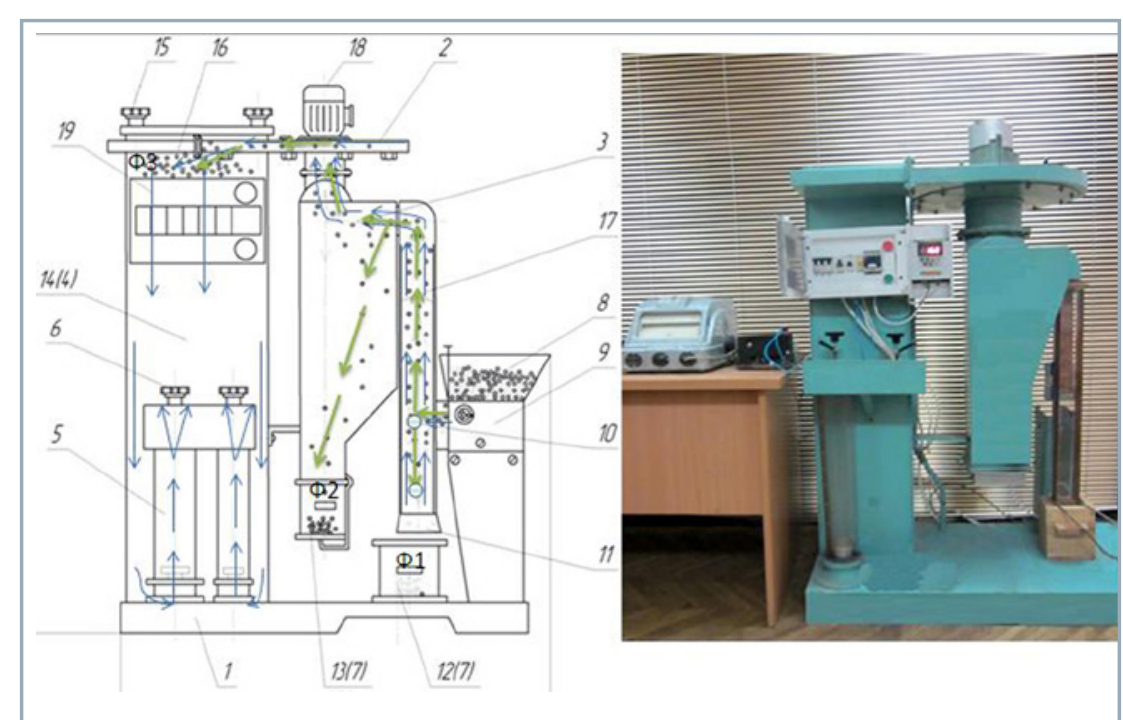

Figure 3 General view (A) and technological scheme (B) of the pneumatic electric separator seed fractions: F1 - weed, F2 - main crop, F3 - light admixtures; directions of movement: air $\longrightarrow$, seedse $\longrightarrow$

1 - bed; 2 - fan; 3 - towering separator; 4 - filter section; 5 - air flow measuring devices; 6 - speed regulation device; 7 - seed containers; 8 - loading bunker; 9 vibration feeder; 10 - separation channel; 11 - retractor hole; 12,13 - containers for seeds; 14 - filter section; 15 - bolts; 16 - filter section cover; 17 - electrodes; 18 - electric engine; 19 - control unit

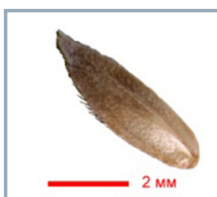

A

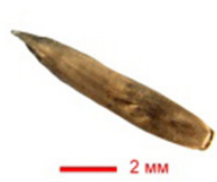

B

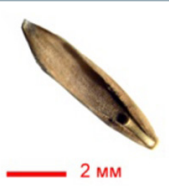

C

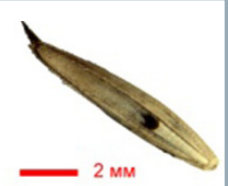

D
Figure 4 Electronic photographs of perennial grasses seeds ( $\mathrm{A}$ - meadow fescue; $B$ - perennial ryegrass) and their main impurities ( $C$ - lungwort; $D$ couch grass)

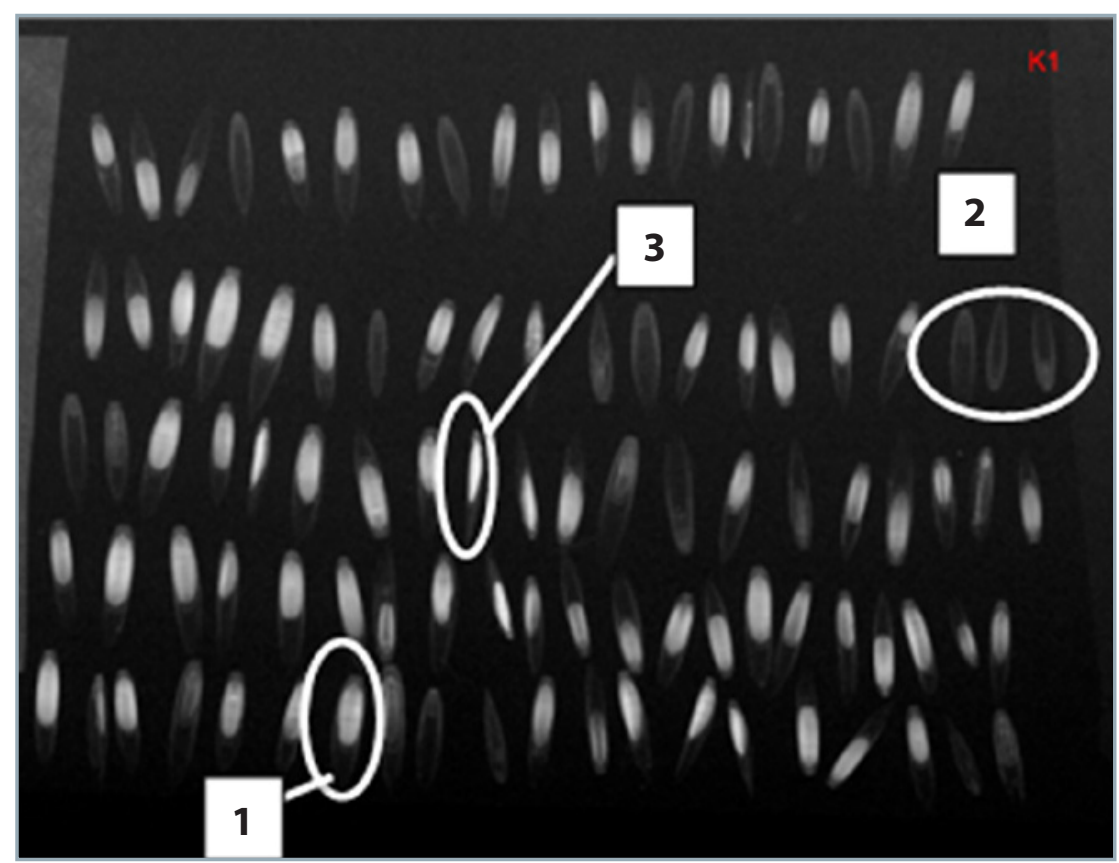

Figure 5

X-ray photographs of sample seeds of perennial cereal grasses

1 - quality crop seed; 2 - substandard seeds without embryo; 3 - shrunken seeds and improve the existing separating machines.

Evaluation of the morphological characteristics of studied seed varieties of cereal grasses and their hard-todivide impurities was performed on the basis of analysis of the photographs of their surfaces obtained with the electron microscope (Figure 4).

The analysis of photographs shows that the seeds of perennial cereal grasses are by their appearance very similar to the seeds of their hard-todivide impurities. They all are: dark yellow; lanceolate, in the form of an elongated ellipsoid; convex on one side, and on the other - on the part of the embryo - with an elongated groove; the keel is covered by short rough hairs. Only the seed of couch grass has a characteristic difference the presence of a curved spine on the top.

The substantial similarity of the investigated seeds is confirmed by the results of their basic physical and mechanical properties, which are presented in Table 2.

Table 2 with dimensional characteristics analysis shows that the difference of mixture components by length, width and thickness is negligible. This confirms that to separate couch grass and lungwort seeds from the seeds of perennial cereal grasses, applying size characteristic is not relevant and it is impossible.

These coefficients of friction angles show the following. The values for friction angles of grass seeds and weed seeds on belting are almost the same and are $23-25^{\circ}$. Other angles of friction surfaces show the following: perennial ryegrass and false oat-grass is $10-14^{\circ}$, for orchard grass $13-14^{\circ}$ and meadow fescue 13-16 . Regarding Bromus inermis seeds, the angle of equilibrium on the glass and foil is $9^{\circ}$ and on steel $6^{\circ}$. But, the value of couch grass angle is somewhat larger at $18^{\circ}, 17^{\circ}$ and $19^{\circ}$. These values do not show any significant differences in the values of angles of equilibrium with the seeds of cereals. This suggests that couch grass can be separated from cereal grass seed mixtures only partially, suffering heavy losses during the processes when frictional surfaces were used as an additional working body. The research of surface friction angles of lungwort seeds coincides with those 


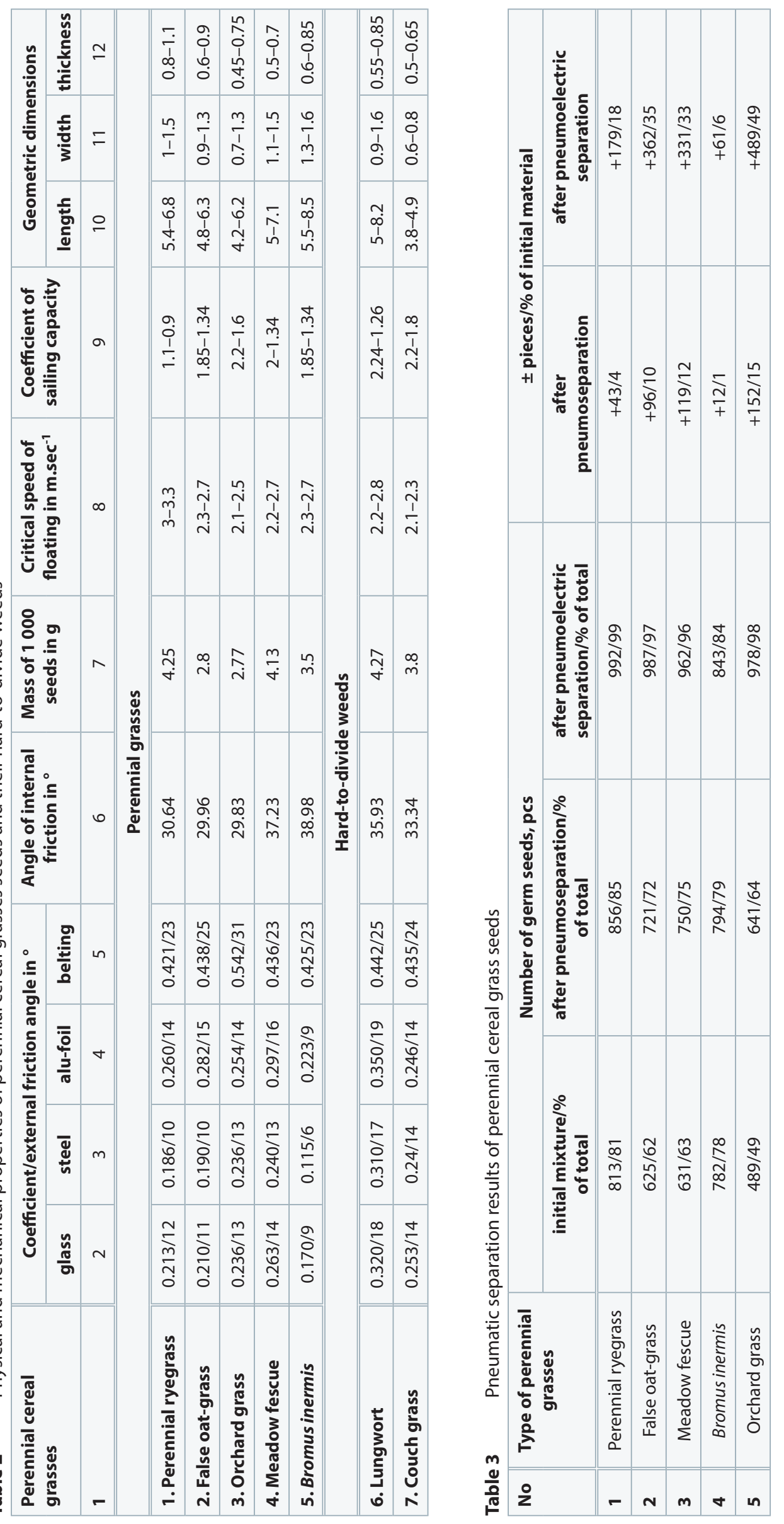


calculated for crop seeds, which makes their separation impossible.

These data prove that the usage of friction working parts of seed separating machines is inappropriate due to inability to use the shape and surface conditions of mixture components as a factor of divisibility.

The use of aerodynamic properties shows little difference of critical speed of floating for both cereal grass seeds and weed seeds. By means of pneumatic separation, perennial ryegrass can be partially separated from couch grass because their seeds have little difference.

The intensification of the process of pneumatic separation of mixtures can be possible due to the use of electric field in the working channel as an additional working body. This statement is consistent with the results of experiments on separation of biologically inferior, dead seeds lacking an embryo. There are two main adjustable

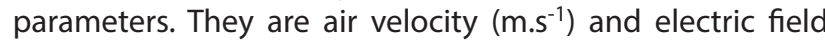
voltage $\left(\mathrm{kV} . \mathrm{cm}^{-1}\right)$.

To determine the efficiency of separation, $\mathrm{X}$-rays were taken for initial and separated mixture (Figure 5).

The results of pneumatic separation are presented in Table 3.

Table 3 shows the inefficiency of the traditional technology of post-harvest seeds handling because of the inferiority of seeds without embryos. The occurrence in orchard grass is higher at $51 \%$ and lower in perennial ryegrass at $19 \%$. Some of them can be separated during the pneumatic separation process. Their content is still quite high, from $35 \%$ to $15 \%$. The greatest effect possible is by the introduction of pneumatic separator body into the vertical channel of electric field. Due to this selective action, a complete separation can be made from one to another. In this way, we can increase the quality of sowing material of grass seed that would contain less than $4 \%$ of poor-quality seeds, except for Bromus inermis.

The results obtained prove the use of such a technology as pneumatic electric separators with high voltage electric field for small seed mixtures of perennial cereal grasses.

\section{Conclusions}

1. Conventional post-harvest treatment of mixtures of small seed crops is inadequate. Crops cover about 20\% of farmland in Ukraine. The current process does not comply with existing standards. This is due to a high number of impurities of weeds and a large number of impurity seeds without embryos.

2. The existing system of separation is impractical and impossible because of the size and shape of seeds, the condition and form of their surfaces, and, of course, their critical speed of floating.

3. Using the pneumatic electric separation method with high-voltage electric field as an additional working body can intensify the process of separating mixtures. Due to its selective action on quality seed and the seed without embryo, it makes it possible to separate them one from another, bringing the total less than $4 \%$.

\section{References}

CHYZHYKOV, A.G. 2001. Status of mechanization and prospects of development of post-harvest handling and storage of grain and seeds. In Research of Science and Engineering in AIC, vol. 11, pp. 17-20.

DADAK, V.O. 2013. Improving of pneumatic separator for small seed crops. In Mechanization and Electrification of Agriculture. InterDepartment Collection of Works, vol. 97, pp. 495-501.

DSTU 7160. 2010. Seeds of vegetables, melon field, fodder and aroma crops. Variety and sowing qualities. Technical specifications. KOVALYSHYN, S.Y. - SHVETS, O.P. - GRUNDAS, S. - TYS, J. 2013. Use of the electro-separation method for improvement of the utility value of winter rape seeds. In International Agrophysics, vol. 27, pp. 491-494.

KOVALYSHYN, S.Y. 2014. Improving the efficiency of pneumatic separation of forage grass seeds. In Technical Systems and Technologies in Livestock, vol. 144, pp. 25-232.

KOVALYSHYN, S.Y. 2013. Pneumatic electric separator for seeds. Scientists Lviv. Agr. University : Catalogue of Innovations, vol. 13, $48 \mathrm{pp}$.

ZAIKA, P.M. - MAZNEV, G.E. 1978. Separation of seed by physics and mechanical properties. Moscow : Kolos, 287 pp.

TARUSHKYN, V.I. 2007. Dielectric seeds separation. Thesis (Dr. of Eng. Sciences). Moscow. 401 pp.

ZHUK, O.Y. - SYCH, Z.D. 2012. Selection of vegetables. In Agrarian Science. 324 pp. 